Fisheries Research

March 2018, Volume 199 Pages 158-170

http://dx.doi.org/10.1016/i.fishres.2017.12.001

http://archimer.ifremer.fr/doc/00417/52869/

(C) 2017 Elsevier B.V. All rights reserved.

\title{
Towards a spatial integrated stock assessment model for European hake northern stock
}

\author{
Vigier Audric ${ }^{1,2,{ }^{*}}$, Mahévas Stephanie ${ }^{1}$, Bertignac Michel ${ }^{2}$ \\ ${ }^{1}$ IFREMER, Écologie et Modèles pour l'Halieutique, Nantes, France \\ ${ }^{2}$ IFREMER, Laboratoire de Biologie Halieutique, Plouzané, France \\ * Corresponding author : Audric Vigier, email addresses : audric.vigier@ifremer.fr ; \\ audric.vigier@gmail.com
}

\begin{abstract}
:
European hake (Merluccius merluccius) is a key species in the management of several mixed fisheries in the north-east Atlantic where regional spatial management plans are being set up. The wide spatial distribution of hake and the lack of knowledge of some processes involved in its spatial dynamics could hamper the assessment and management of hake.

To help understand the processes, we implemented a spatial version of the Stock Synthesis stock assessment model for northern hake, including available data on this stock and the associated fisheries. For the 1978-2012 time series, the model distinguished the Bay of Biscay, the Celtic Sea and a northern area aggregating the West of Scotland and the North Sea. The model considered an agestructured population for each age class and area, a seasonal migration, global recruitment allocated to areas and fishing fleets for each area. Parameters for stock and exploitation spatio-temporal dynamics were estimated by likelihood maximization for each quarter and area.
\end{abstract}

The comparison of spatial and non spatial models goodness of fit showed they were close, although the fit to abundance indices slightly improved with the spatial model.

Fishing mortalities, spawning stock biomasses and recruitments were slightly different from the current assessment model estimates, essentially at the beginning and the end of the time series. On average over the time series, fishing mortality estimates relative to the abundance were higher in the Bay of Biscay than elsewhere, spawning stock biomass estimates were higher in the Celtic Sea than elsewhere, and recruitment occurred mainly in the Bay of Biscay. Finally, the final spatial model estimated a strong movement from the northern area to the Celtic Sea. The final spatial model is a step towards a spatial assessment and management of the stock.

Keywords : Stock Synthesis, Integrated analysis, Spatially explicit model, European northern hake, Merluccius merluccius 


\section{Main text}

\section{Introduction}

40 European hake (Merluccius merluccius) is a demersal fish widely distributed over the north-

41 east Atlantic shelf from Mauritania to Norway and in the Mediterranean Sea (Casey and

42 Pereiro, 1995). It has been one of the most important commercial species in the north east

43 Atlantic demersal fisheries since the first half of the twentieth century (Murua, 2010).

44 European hake is assessed as three distinct stocks: northern, southern, both assessed by the

45 International Council for the Exploration of the Sea (ICES), and Mediterranean. This study 
46 focused on the northern stock distributed from the northern Bay of Biscay to the Kattegat

47 (ICES Division 3a, Sub-areas, 4, 6, 7, Divisions 8a, b, d, see figure 1).

49 Following concerns in the late 1990s about the low stock biomass and the possibility of

50 recruitment failure, a range of measures were introduced (EC, 2001a, 2001b, 2002) in order to

51 improve selectivity and protect juveniles, and a recovery plan was subsequently adopted (EC,

52 2004). These management measures, coupled with several years of high recruitment, lead to a

53 stock recovery, with an increase of the spawning stock biomass (SSB) well above the

54 precautionary approach level since 2009 (ICES, 2016). With the reformed Common Fishery

55 Policy (EU, 2013), the European Commission is currently developing regional multi-annual

56 management plans to address mixed fishery issues (STECF, 2015). Several framework

57 directives, e.g. the Maritime Spatial Planning Directive (EU, 2014) and the Marine Strategy

58 Framework Directive (EU, 2008), have provided the basis for the measures drawn up by the

59 European Commission.

61 Hake is one of the main species included in the multiannual management plans for Southern

62 and Northern European Western Waters (STECF, 2015) recommending a management at

63 regional scale with target ranges of fishing mortality for individual species. As the hake stock

64 is distributed over several management regions, it is of importance to consider the spatial

65 distribution and dynamics of the stock and of the fleets exploiting it. This may improve the

66 stock management, as it may allow to define management measures consistent with the spatial

67 variations of the stock and fleet dynamics.

68 Since 2010 (ICES, 2010) the northern stock has been assessed using Stock Synthesis, version

69 v3.24f (SS3) (Methot and Wetzel, 2013) based on length-structured data, avoiding the use of a 
70 potentially biased and uncertain age-length key (de Pontual et al., 2006). The current

71 implementation of the SS3 assessment model for hake is, however, non spatial, ignoring the

72 spatial variations of several biological processes and fishery related metrics, with spatially

73 invariant selectivity patterns for some fleets, recruitment, and the absence of migrations. This

74 may affect estimates of biomass and length structure (Cadrin and Secor, 2009; Cope and Punt,

75 2011; Gertseva and Cope, 2011), and hence stock management.

76 A spatial model can account for the spatial distribution of the fishing mortality associated with

77 each fleet and thus reduce the potential bias in a non spatial model (Pelletier and Mahevas,

78 2005), improving estimates of biological processes parameters and biomass (Garrison et al.,

79 2011; McGilliard et al., 2015). Furthermore, such models can potentially reveal additional

80 information on stock dynamics and spatial variations in the impact of fishing, to improve the

81 accuracy of management indicators and the evaluation of spatial management plans (Hampton

82 and Fournier, 2001; Montenegro et al., 2009; Moustakas et al., 2006; Russo et al., 2014).

84 Currently, the background knowledge required for implementing spatially structured stock

85 dynamics for hake is limited. Little is known about the annual variations in recruitment in the

86 Bay of Biscay, the Celtic Sea and the northern nurseries. Hake is unevenly distributed over its

87 range of distribution and its spatial patterns and habitat preferences are poorly understood.

88 Mature hake migrate westwards from the shelf in autumn and winter and aggregate offshore

89 for spawning (Poulard, 2001; Woillez et al., 2007). A northwards spawning migration, through

90 the reproductive season, has been proposed by several authors (Alvarez et al., 2004; Guichet,

91 1996) and a migration from the Celtic shelf to the Bay of Biscay has also been proposed

92 (Guichet, 1996), but neither of these migrations has yet been confirmed. Recently, migration

93 between the West of Scotland and the North Sea has also been proposed (Baudron and

94 Fernandes, 2015). All these migrations are difficult to estimate with the available models and 
95 data, and given the lack of appropriate tagging data (Bertignac et al., 2012; Drouineau et al., 96 2010).

98 Several spatial models have been proposed to account for the spatial features of hake northern

99 stock and estimate uncertainties. Drouineau et al. (2010) proposed a spatial model fitted to a

100 short time series to improve knowledge of hake growth and migrations. Bertignac et al.

101 (2012) proposed a spatial Stock Synthesis model fitted to a long time series to provide

102 information for the development of spatial management of hake, such as on the spatial

103 distribution of hake. These preliminary studies provided new insights into the spatial stock

104 dynamics of hake, such as estimates of spatial distribution, recruitment and fishing mortality,

105 and migrations. They also highlighted several limitations of the models, such as confounding

106 between model estimates (Bertignac et al., 2012), a failure to reproduce spatial patterns, such

107 as mature hake aggregation on the Celtic Sea shelf, or a migration from the Bay of Biscay to

108 the Celtic Sea (Drouineau et al., 2010). To improve their models, they suggested that further

109 exploration was required on the assumptions about selectivity patterns, the definition of the

110 migrations, the allocation of recruitment to each area and on alternative spatial structures.

111 Furthermore, Drouineau et al. (2010) excluded the North Sea and the West of Scotland, and

112 Bertignac et al. (2012) included them aggregated with the Celtic Sea. Yet, there have been

113 recent changes in stock dynamics in the North Sea (Baudron and Fernandes, 2015) calling for

114 a more precise modeling of this area. An improved model, addressing the issues described

115 above, is required to improve knowledge of hake stock dynamics.

117 Spatially structured Stock Synthesis models have already been implemented for other species 118 and fisheries: Day et al. (2015) assessed toothfish stocks in the Macquarie Island fishery, 119 Kolody, 2010; Sharma, 2014 assessed an Indian Ocean Swordfish Fishery, Thorson and 
120 Wetzel (2015) assessed canary rockfish stocks off the US West Coast, Cass-Calay et al. (2015)

121 assessed red snapper stocks in the Gulf of Mexico, all using a spatially structured Stock

122 Synthesis model. Among others, they noticed the high sensitivity of their models to poorly-

123 known processes, and that while developing a more complex model, one may replace

124 problematic assumptions with other problematic assumptions. Hence the implementation of

125 such models requires an accurate specification of the model, and, more specifically, an

126 appropriate spatial structure and scale given the available knowledge, data and management

127 needs. Finally, spatial assessment should be treated with caution as misspecified assumptions

128 of spatial features and lack of data may lead to a poorly performing model (Maunder and

129 Piner, 2017; Punt et al., 2015).

131 From the non spatial Stock Synthesis model currently used to assess the northern hake stock

132 (ICES, 2016), we have implemented a spatial Stock Synthesis model, describing explicitly the

133 Bay of Biscay, the Celtic Sea and a northern area including the West of Scotland and the

134 North Sea. The population dynamics component of the model can, therefore, allow for spatial

135 variations in the demographic structure, the recruitment and migration estimates. Selectivity

136 patterns and fishing mortalities ${ }^{1}$ for each commercial fleet and indices of abundance from

137 scientific surveys are calculated for each area. This spatial Stock Synthesis model was fitted

138 to spatially disaggregated catch and survey data. Statistical metrics of goodness of fit were

139 used to evaluate its relevance for integrated assessment of the northern hake stock. Spatial and

140 global estimates of biomass are then discussed to assess whether this spatial model provides

141 new insights into the fishery. Finally we discussed lessons raised by the modeling process for

142 implementing spatial models using currently available data and scientific knowledge.

1 Here fishing mortalities are relative to the abundance, see formulae in Appendix B. 


\section{3 \\ 2 Material and methods}

\subsection{Model description}

$145 \quad$ 2.1.1 Current non spatial Stock Synthesis assessment model

146 Stock Synthesis is a statistical framework for calibration of population dynamics model using

147 a diversity of fishery and survey data (Methot and Wetzel, 2013) providing flexibility for

148 spatially and seasonally explicit modeling. It is designed to accommodate age structure at a

149 seasonal time scale with multiple stock sub-areas, and allows for the description of a length

150 structure to fit length composition data..

151 Northern hake is currently assessed using a non spatial, age-length structured Stock Synthesis

152 model, encompassing the whole northern stock distribution area. In this model hake growth

153 was described by a von Bertalanffy relationship and the distribution of lengths for a given age

154 were assumed to be normally distributed. Recruitment was modeled by a Beverton-Holt

155 stock-recruitment relationship, and is seasonally distributed in proportions that vary from year

156 to year. Due to lack of knowledge on recruitment processes, the steepness was set to 0.999,

157 leading recruitment almost independent of spawning biomass. Maturity-at-length was

158 described using a time invariant logistic ogive, without distinction between sexes. Weight-at-

159 length were estimated from a fixed length-weight relationship. Natural mortality was set to

160 0.4. This high value was set after tagging results showed that previously hake age was

161 overestimated by a factor of two (de Pontual et al., 2006). The model stock dynamics were

162 assumed to be spatially invariant. Seven fleets and 7 scientific surveys were described (see

163 Table A.1), some encompassing several areas at a time, such as the Bay of Biscay and the

164 Celtic Sea. Some spatial variations in fishing dynamics were included, as some fleets and

165 selectivities describe fishing fleets operating in only some areas, such as the Spanish trawlers

166 operating only in the Bay of Biscay or only in the Celtic Sea, or a mix fleet operating mostly

167 in the West of Scotland and in the North Sea (see table A.1). Further details on this non spatial 


\section{$170 \quad$ 2.1.2 Towards a spatial assessment model}

171 In this study, the spatial model was developed from a non spatial model through the

172 implementation of several intermediate models, with a step-wise increase in complexity to

173 provide a better understanding of the final spatial model fit. Two of these intermediate

174 models, and the spatial model are described through their differences in main features, which

175 are summarized in table 1. More details on the intermediate models are given in Appendix A.

176 The first intermediate model (intermediate 1 in Table 1) modelled one area, as in the non

177 spatial model, but with an implicit spatial fleet definition (table 2) so that each fleet operated

178 only in the northern Bay of Biscay (8a, b, d), or only in the Celtic Sea (7a-c, f-k), or only in a

179 northern area merging the West of Scotland, the North Sea, Kattegat and Skagerrak $(3 a, 4,6)$

180 (see figure 1). Longliners and gillnetters were aggregated, since complex configurations

181 distinguishing these 2 fleets lead to convergence issues given the high number of parameters

182 required to describe fleets fishing intensity (see appendix A). Given that these fleets both fish

183 bigger individuals than other fleets, this also justified a merge, which still allows a spatially-

184 explicit modelling. Non-Nephrops trawlers were split between trawlers fishing in shallow (E)

185 or in deep (W) waters to improve the fit given the dissimilarities between the exploitation

186 patterns of these fleets. Only one fleet operated in the northern area, combining all hake

187 métiers in this area. A specific selectivity function was estimated for each fleet. For the fleets

188 discarding hake (TRAWL_FISH_CS_W, TRAWL_FISH_BOB_W, TRAWL_NEP,

189 OTHERS), a retention function separated the landed and discarded fractions of the catch.

190 These functions were the same as those defined by (ICES, 2014). Although

191 TRAWL_FISH_CS_E and TRAWL_FISH_BOB_E fleets are known to discard, this was not

192 modeled as available information on their discards is not reliable enough. The EVHOE survey 
193 was split between the Bay of Biscay and the Celtic Sea, and it was assumed that both EVHOE

194 surveys had the same selectivity pattern.

195 The second intermediate model (intermediate 2 in table 1) was spatially explicit as 3 areas

196 were described: the Bay of Biscay, the Celtic Sea, and the northern area (Figure 1). The stock

197 was split into these three areas, with the same stock dynamics and no migration. The

198 recruitment was distributed over these three areas in proportions that could vary from year to

199 year. Each fleet defined in intermediate 1 model was explicitly associated to the area

200 corresponding to its operating fishing area, and therefore its selectivity pattern affected the

201 length structure of the stock in the area. Three additional surveys operating in the northern

202 area were included to capture more information on small individuals in this area: NS-IBTSQ1

203 and NS-IBTSQ3, the IBTS surveys in the North Sea winter and summer respectively, and the

204 SWC-IBTS survey in the West of Scotland in autumn. Scientific surveys operating with the

205 same vessel in different areas (e.g EVHOE_CS and EVHOE_BOB) or in different seasons

206 (e.g. NS-IBTSQ1 and NS-IBTSQ3) were assumed to have strictly the same selectivity

207 pattern.

208 Given to the literature, there are several potential migrations of the stock between the three 209 areas (Table 3). Several studies (Alvarez et al., 2004; Baudron and Fernandes, 2015; Casey

210 and Pereiro, 1995; Guichet, 1996; Korta et al., 2015) indicate that some seasonal migrations

211 may occur between the Bay of Biscay and the Celtic Sea, on the one hand, and between the

212 West of Scotland and the North Sea on the other hand, linked to both spawning and

213 environmental conditions. Based on those studies, we considered migration from the Bay of

214 Biscay to the Celtic Sea at the end of winter and in the opposite direction in the other seasons.

215 Likewise, we considered migration from the Celtic Sea to the northern area, at the end of

216 winter and spring, and in the opposite direction in the other seasons. All these migrations were

217 assumed to be the same every year. A comprehensive description and the input files of this 
218 model are provided in Appendix C, as well as a description of the estimation procedure.

$220 \quad$ 2.1.3 Model assessment

221 Models with various levels of complexity were fitted (see Table A.2 and Appendix A). The

222 estimation procedure was assumed to have converged if the approximation of the Hessian

223 matrix was positive definite and the gradient of the objective function value was below an

224 empirical threshold of 0.01: below this threshold, it was assumed that an optimum of the

225 objective function was reached. The model was assumed to be identifiable if the rank of the

226 estimate of the Hessian was equal to the number of parameters to be estimated (Drouineau,

227 2008; Viallefont et al., 1998) The quality of the parameter estimates was tested in various

228 ways, following (Cass-Calay et al., 2014):

229 - The variance-covariance matrix, estimated by calculating the inverse of the Hessian matrix,

230 was analyzed to check for any abnormal parameter redundancy, i.e. any high correlation

231 between two unrelated estimated parameters.

232 - A jitter analysis (Cass-Calay et al., 2014), i.e. the analysis of runs with different initial

233 parameter values, was used to ensure the model was robust to changes in the initial values.

234 - A likelihood profile was calculated for the virgin recruitment level parameter to ensure that

235 there was enough information in the data to estimate this parameter.

236 - Sensitivity to the most recent years of data was tested using a retrospective analysis.

238 The quality of fit of the non spatial, intermediate and spatial models were compared using two

239 indices representing the divergence between predicted and observed time series of catch and

240 discards for each fleet and of survey indices: 
241 - IndR, which is based on the correlation coefficient R introduced in (Taylor, 2001):

$242 \quad \operatorname{IndR}=\frac{R+1}{2}$

243 where $R=\frac{\frac{1}{N} \sum_{n=1}^{N}\left(o_{n}-\bar{o}\right)\left(p_{n}-\bar{p}\right)}{\sigma_{o} \sigma_{p}}$, where $N$ is the number of observations in the time series,

2440 . is a normalized observation series, $p$. is the associated normalized model prediction

245 series, $\bar{o}$ is the mean of the normalized observations, $\bar{p}$ is the mean of the normalized

246 estimates, $\sigma_{o}$ is the standard deviation of the observation series and $\sigma_{p}$ is the standard

247 deviation of the prediction series. An IndR value of 1 indicates $100 \%$ correlation between $o$

248 and $p$ series, a value of 0,5 indicates zero correlation, a value of 0 indicates $100 \%$

249 anticorrelation.

250 -IndRMSD, which is based on the pattern root mean square difference E' introduced in Taylor

251 (2001): $\operatorname{IndRMSD}=\exp \left(-3 \sqrt{\left(\frac{\bar{o}-\bar{p}}{\bar{o}}\right)^{2}} E^{\prime}\right)$, where $\quad E^{\prime}=\sqrt{\frac{1}{N} \sum_{n=1}^{N}\left(\left(o_{n}-\bar{o}\right)-\left(p_{n}-\bar{p}\right)\right)^{2}}$. An

252 IndRMSD value of 1 indicates that $o$ and $p$ series are perfectly alike. The closer is IndRMSD

253 of 0 , the more the series differ. This index characterizes the amplitude of variations, seen as

254 discrepancies to the series main values, and scale. For length distribution data series, IndR and

255 IndRMSD are calculated for each length bin, then averaged over the bins.

256 Usually, Taylor diagrams are used to display such indices and compare models fit (see

257 (Taylor, 2001) for full explanation), however, to improve the readability, we plotted IndR and

258 IndRMSD indices on a small number of radar charts. The right part of a radar chart shows the

259 ability to reproduce the variability of a series with IndR, and the left part shows the

260 accumulated deviations of the mean of the series with IndRMSD.

261 Models were compared whenever possible using pseudo-AIC. The model with the smallest 
262 pseudo-AIC was considered as the most likely for a given number of estimated parameters.

263 The pseudo-AIC is based on AIC (Akaike, 1974), except the negative log likelihood is

264 replaced by the objective function (weighted log likelihood):

265 pseudo-AIC $=2 * O F+2 * n$

266 where $n$ is the number of estimated parameters. This selection procedure was carried out for

267 the models for which the estimation procedure converged, which were identifiable, which had

268 no estimated parameters at the bounds of the range for which they were defined and

269 reproduced the main features of the observations dataset.

\subsection{Data}

272 The data availability is shown in Figure 2. All the data were available quarterly, except for

273 landings by weight and landing length-frequency distribution between 1978 and 1989 which

274 were available annually. For this period, landings by weight were distributed between quarters

275 using the mean seasonal distribution between 1990 and 1994 for each fleet. For some time

276 steps, fleets and data categories, there may be gaps in the data (see figure 2):

277 - Landing data depends on the country and are derived from sales notes, logbooks, auction

278 hall sales notes and sampling data.

279 - Discard data and discard length-frequency distributions were collected on-board by

280 observers, and then raised by national institutes.

281 - Length-frequency distributions were sampled at auction halls for landings.

282 - Relative abundance indices and the associated length-frequency distributions come from 11

283 surveys listed in table 2. Abundance indices were calculated using stratified sampling

284 aggregated for each area. There are 2 main differences in the data between the non spatial and 285 the spatial models: 1) as the EVHOE survey has been split into EVHOE Bay of Biscay and 
286 EVHOE Celtic Sea, the spatial models were able to use the data from 1987-1996, when the

287 survey was carried out in the Bay of Biscay only; 2) data from SWC-IBTS and NS-IBTSQ1 288 and Q3 has been added;

\section{Results}

\subsection{Goodness of fit}

292 For all intermediate models, the estimation procedure converged and estimates were

293 considered valid, as they fulfill the criteria of convergence, identifiability and estimation

294 procedure described in section 2.1.3. Concerning the spatial model, in terms of pseudo-AIC

295 and convergence, the model with migration pattern including only the movement from the

296 northern area to the Celtic Sea at season 3 provided the best performances (see Appendix A,

297 and table A.2), hence it was selected as our final spatial model. For the latter model, more

298 diagnostics were carried out. The jitter analysis showed that the estimation procedure was

299 sensitive to the initial point, and so a set of initial points was used to chose the best solution

300 possible (see Appendix A for details). Also, the likelihood profile (see Appendix A, figure

301 A.1) showed that the final spatial model estimation procedure converged globally. Even

302 though the profile is smooth, the estimation procedure had to be run with several initial points

303 before reaching a global convergence for some parameter values, indicating instabilities

304 between local and global convergences for the final spatial model. Finally the retrospective

305 analysis (figures A.2 and A.3) showed that the final spatial model was sensitive to the

306 inclusion of recent years data at global and regional scales, especially on spatial recruitment

307 allocation, and on fishing mortalities and spawning stock biomass at the end of the time

308 series. 


\subsection{Comparison of model performance}

311 All IndRMSD and IndR indices are displayed on radar charts (figure 3) on one broken line per

312 model, the right parts of charts displaying IndR, and the left parts of charts IndRMSD; rows

313 display from top to bottom indices on landings, discards and abundance indices, columns

314 from left to right indices on length compositions and in weight. The radar charts show that for

315 IndR and IndRMSD, all models perform similarly on normalized length compositions of

316 catch, discards and abundance indices (figure 3A, B \& C) and on normalized catch and

317 discards by weight and abundance indices (figure 3D, E \& F). The final spatial model

318 performs similarly or slightly better than the non spatial model on landings length

319 compositions indices (figure 3A), even if the non spatial model still performs the best on

320 some of these indices. The final spatial model has similar or better performances than the non

321 spatial on most of discards in weight indices (figure 3E). On abundance indices, the

322 intermediate 2 and final spatial models perform in general better than other models (figure

323 3F). This indicates benefits of using a spatial model on processes linked to landings length

324 compositions, discards and abundance indices.

326 IndRMSD for the normalized length structure of the catch (figure 3A) are higher for the final

327 spatial model than for the non spatial model for GILLLONG, TROTH and SPTR7 fleets,

328 IndR is higher for the final spatial model than the non spatial for GILLLONG and SPTR7.

329 This indicates a better estimation of the catch length composition, which may be linked to a

330 better modeling of fishing mortalities or selectivities for these fleets. This is however not the

331 case for the OTH fleet indices and TROTH IndR, where the final spatial model performs

332 worse than the non spatial, but better than the other models. These differences are seen

333 between the fit of the non spatial model and the fit of intermediate 1 model. Adding an

334 explicit spatial dimension without migration (intermediate model 2) brings further slight 
335 improvements. Adding a migration to the model improves only OTH IndRMSD. The fact that

336 the final spatial model brings only few improvements may indicate that the data contains very

337 few information on migration processes.

339 IndRMSD and IndR for normalized length structure of discards, abundance indices and

340 landings in weight (figure 3B, C \& D) show that the predictions of all models are close. We

341 notice only a few discrepancies, the intermediate model 1 performing better on SPTR8 IndR

342 for discards length compositions. IndRMSD for RESSGASCQ1;3 are higher for the non

343 spatial model than the final spatial model, liekwise for RESSGASCQ1 IndR; whereas

344 IndRMSD for EVHOE and RESSGASCQ2 are higher for the final spatial model than the non

345 spatial. Apart from these few discrepancies, we cannot bring out benefits or drawbacks of

346 using a spatial model linked to the modeling of discards and abundance indices length

347 compositions, and of landings in weight.

349 IndR for discards by weight (figure 3E) are similar for all models, however, IndRMSD for

350 NEP and SPTR7 fleets are better for the final spatial model than the non spatial model, which

351 may be linked to the modelling of these fleets retention patterns, even though NEP IndR is

352 slighly lower for the final spatial model than the non spatial. Some of the previous indices

353 may improve or worsen when adding an implicit spatial fleet design (intermediate model 1),

354 an explicit spatial dimension (intermediate model 2), or a migration (final model), making it

355 hard to bring out which assumption may improve the modeling of discards in weight. These

356 performances are worse than for landings, given the higher uncertainties in the discard data.

358 IndRMSD and IndR for the normalized abundance index (figure 3F) are similar or slightly 
359 higher for most of surveys for the intermediate 2 and final spatial models than the non spatial.

360 Intermediate model 1 improves predictions mostly for IGFS and RESSGASCQ1, but not for

361 RESSGASCQ2-4 surveys. The spatially-explicit intermediate model 2 improves predictions

362 for PORCUPINE and RESSGASCQ2-4, but not Q1. Finally, the final spatial model worsens

363 PORCUPINE indices, and does not bring further improvement. It performs best than the non

364 spatial model for RESSGASCQ2-4 and IGFS surveys. Since we assumed that abundance

365 indices are directly proportional to abundance, this indicates a better estimation of abundance

366 or catchabilities by the final spatial model for these surveys. IndR values for the abundance

367 indices are smaller than for the other data series in general. This is explained by the high inter-

368 annual variability of survey indices of abundance.

370 We observed that the final spatial model is the most parsimonious, since its pseudo-AIC is the

371 lowest among all the models with various levels of complexity that were tested (Appendix A).

372 This model was therefore chosen for analysis of the fit and predicted dynamics.

\section{$374 \quad 3.3$ Analysis of final spatial model fit}

375 The comparison of observed and predicted length-frequency distributions aggregated over

376 time steps (Figure 4) and the mean Pearson residuals over time steps (Figure D.1) shows that

377 the final spatial model fits well the observed length-frequency distributions. This is

378 particularly true for commercial fleets and landings (panels F to I, O to Q and V), for which

379 the differences between observations and the model results are small and the mean Pearson

380 residuals are close to 0 . Note that the largest discrepancies on the fit appear at the quarter

381 scale (see Supplementary Material). Furthermore, for fleets operating in two different areas

382 with the same gear, the peaks in observed length-frequency distributions do not occur at the 
383 same lengths in the Bay of Biscay and the Celtic Sea, which is well reproduced in the model

384 predictions. This demonstrates the ability of the model to accurately estimate the selectivity

385 pattern of each fleet.

387 The model also performs well in predicting length-frequency distributions for the scientific 388 surveys (Figures 4 and D.1 panels A to E, L to N, and S to U). It must be noted that the

389 EVHOE surveys, operating in different areas of the final spatial model, have the same

390 selectivity function. The ability of the model to capture the differences observed in length

391 frequency distributions in different areas demonstrates its ability to describe spatial variations

392 not only through selectivities, but also through the spatial structure of the stock.

393 Nevertheless, the model has a relatively coarse structure and cannot account for all observed

394 spatial variations. In the Celtic Sea for instance, the model did not fit the PORCUPINE survey

395 length-frequency distributions very well (Figures 4 and D.1, panel N), even though a

396 selectivity pattern specific to this survey is estimated. For this survey, occurring only on the

397 Porcupine Bank, an area where mainly large hakes are present, the observed length frequency

398 distributions are very different from the other surveys conducted on the Celtic Sea shelf

399 (IGFS, EVHOE_CS, Figures 4 and D.1, panels L and M), and slightly erratic (see

400 Supplementary Material). Different selectivities cannot account for all the differences in 401 length-frequency distributions inside a particular area of the model, as they apply on the same 402 abundance length compositions. In the northern area, there is the same difference between the 403 well-fitted West of Scotland SWC-IBTS survey, and the poorly fitted and erratic North Sea 404 NS-IBTS surveys (Figures 4 and D.1, panels S to U, and Supplementary Material) with the 405 survey selectivities in the final spatial model only accounting partially for the northern area 406 spatial structure as shown by the different predicted length-frequency distributions for the 407 surveys in the area. 
408 The final spatial model provides a generally good representation of the seasonal variation in

409 length-frequency distributions, except for RESSGASCQ3 (Figures 4 and D.1, panels B to E),

410 for which smaller length classes, corresponding to the arrival of recruits, are a poor fit. This

411 might indicate a poor estimation of the summer Bay of Biscay recruitment levels in the

412 model.

413

414 For the commercial fleets, observations are all well predicted by the model and the only

415 weaknesses are for the mixed fleet OTHERS and for uncertain discard data (see Appendix D,

416 figures D.1 and D.2). The model provides a good prediction of the inter-annual variations of

417 landings and discards by weight (Figure D.2) except for the discards from non-Nephrops

418 trawler fleets (panels I and K) which, could cause the fishing mortality at the end of the time

419 series to be over-estimated in the Bay of Biscay and underestimated in the Celtic Sea.

421 The abundance indices (Figure 5) are also well predicted by the model, especially in the Bay

422 of Biscay and in the Celtic Sea, and the fitted curves are mostly within the confidence bands

423 for each survey. Again, it is interesting to note that the model has difficulty fitting the SWC-

424 IBTS and NS-IBTS survey indices simultaneously (panels I to K). These surveys, conducted

425 in the West of Scotland and North Sea respectively, show different abundance patterns

426 although, in the model, these two areas are aggregated in the same northern area with the

427 assumption that the two surveys harvest a population that is uniform over the whole of the

428 northern area. This is similar to the difficulty of fitting the length-frequency distributions for

429 the surveys, and highlights the problems arising from the coarse spatial structure used in the 430 model. 
4323.4 Perceptions of fishery and stock dynamics: final spatial model versus non spatial model

434 Overall, the final spatial model provides a similar perception of the fishery and stock

435 dynamics to that of the non spatial model (Figure 6) even if the final spatial model estimates

436 are slightly more uncertain, as the wider confidence intervals show. Total fishing mortality

437 (see Appendix B for calculations), SSB and recruitment are similar over most of the time

438 series, but there are some differences at the beginning and the end:

439 - from 1978 to 1986, fishing mortalities and recruitment are estimated to be higher, and SSB

440 in general lower in the final spatial model than in the non spatial model.

441 - from 1987 to around 1994, fishing mortalities and SSB are higher in the final spatial model

442 than in the non spatial model.

443 - from 2006 to 2012, fishing mortalities are estimated to be higher, and SSB lower in the final

444 spatial model than in the non spatial model, except for fishing mortality the last year.

445 Recruitment is lower in the final spatial model, except the last three years, where it increases

446 much more than in the non spatial model.

447 For the last year, SSB and fishing mortality are within precautionary reference points, SSB

448 and fishing mortalitiy are above Maximum Sustainable Yield reference points for both models

449 (see MSY Btrigger, FMSY, Blim, Flim, Bpa and Fpa and their definitions in ICES (2015)).

\subsection{Perception of spatial stock dynamics}

452 The spatial estimates of fishing mortalities, SSB, recruitment, and migrations for the three

453 studied areas provide new insights into the population dynamics of hake (Figure 7).

454 The northern area is productive, with high levels of SSB before 1994, between around 15000

455 and 40000 tonnes, and a recruitment of around $12 \%$ of the total over the time series. The

456 estimate of the proportion of adults migrating to the Celtic Sea during season 3 is high, 
457 around 37\%, giving the Celtic Sea enough biomass to yield the observed high level of catch.

458 The model estimated low fishing mortalities before 1992, mainly below 0.5 which then

459 increased to around 0.75 in 1994 with the SSB dropping to around 3500 tonnes in 1998.

460 Fishing mortalities remained at these high values until 2002 and then dropped to values

461 similar to those at the beginning of the time time series, below 0.5. SSB remained low from

4621994 to 2008 , then strongly increased to almost 40000 tonnes.

463 The Celtic Sea population is abundant, as its SSB is the highest over almost the whole time

464 series. This area is allocated around $15 \%$ of the total recruitment at the beginning of the time

465 series, excepted in 1981, where the proportion reaches around 30\%. This proportion increases

466 between 1990 and 2000 to around 30\%, with inter-annual fluctuations. The recruitment,

467 coupled to immigration from the northern area, partly explain the high estimated SSB in this

468 area, between 20000 and 60000 tonnes. It increases from around 20000 to around 60000

469 tonnes from 1978 to 1986 , then drops back to less than 20000 tonnes from 1986 to 1998 , and

470 then fluctuates around 25000 tonnes, before a steady increase from 2009 onwards to reach

471 around 60000 tonnes in 2012. Over the time series, the fishing mortalities were estimated

472 mostly between and 0.25 and 0.5 , with high inter-annual variability.

473 In the Bay of Biscay, at the beginning of the time series, the SSB was surprisingly much lower

474 than in the northern area, by a factor of two. However, on average over the time series, the

475 Bay of Biscay was allocated around $67 \%$ of the total recruitment, with high inter-annual

476 variability. Coupled to the very high estimates for fishing mortality, almost all over 1 before

477 2006, this indicates the Bay of Biscay population is heavily exploited and renewed. The

478 dynamics are shifting from 2006, with a dramatic fishing mortality drop from around 1,5 to

4790,13 and SSB increase from around 4000 to 76000 tonnes. As for the two other areas of the

480 model, this may be to be linked with the strong recruitment in 2008 and 2011-2012 (Figure

$4816)$. 


\section{Discussion}

484 4.1 Perception of the fishery and stock dynamics supported by the final spatial model estimates

486 In the Celtic Sea and the Bay of Biscay, the increasing SSB estimated by the final spatial

487 model after 2005 was consistent with the increase in landings at the end of the time series for 488 these two areas (Figure D.2, panels A to G) and the high estimated recruitment in 2008 and 4892012 (Figure 5), already estimated by the non spatial model (ICES, 2016). The estimated 490 distribution of SSB or total biomass between the Celtic Sea and the Bay of Biscay was 491 between the values already given in the literature (Bertignac et al., 2012; Drouineau et al., 492 2010). For example, $94 \%$ of SSB was allocated to the Celtic Sea and around $6 \%$ to the Bay of 493 Biscay in the Drouineau et al. (2010) model for 2005 (they did not model the northern area), 494 while, for 2005, the final spatial model allocated around $80 \%$ of SSB outside the northern area 495 to the Celtic Sea. On the other hand, Bertignac et al. (2012) estimated that around 55\% of the 496 total biomass was located in the Bay of Biscay over the whole time series, while the final 497 spatial model estimated only $19 \%$ in the Bay of Biscay (not shown) over the whole time 498 series. This makes our spatial repartition estimates intermediate between these 2 previous 499 models estimates.

500 Also, the estimated spatial pattern of recruitment allocates most recruitment (67\%) to the Bay 501 of Biscay, less (21\%) to the Celtic Sea and least (12\%) to the northern area over the time

502 series (Figure 7). This result is rather expected on the basis of the literature and surveys with 503 known nursery areas mostly located in the Bay of Biscay, then the Celtic Sea (Casey and 504 Pereiro, 1995) and lastly the northern area (Guichet, 1996; Quéro and Vayne, 1997; Werner et 505 al., 2016); the spatial distribution of recruits observed by the EVHOE survey showed higher 
506 recruitment in the Bay of Biscay than in the Celtic Sea (ICES, 2016).

507 The estimates of spatial allocation of recruitment are sensitive to the inclusion of observations

508 on discards and surveys, given that these observations include information on small

509 individuals. Given the high uncertainties on discards data, more information on discards may

510 help to estimate more accurately the recruitment.

512 In constrast, the final spatial model also showed some rather unexpected patterns. Over the

513 earlier period of the time series (1978-1992), the estimates of SSB in the northern area were

514 almost as high as in the later period (Figure 7), and were almost twice those estimated for the

515 Bay of Biscay. This result is somewhat inconsistent with the low level of catches observed in

516 the northern area over the same period (Figure D.2, panel H) which indicated a quasi-absence

517 of hake in the North Sea for the past 50 years (Baudron and Fernandes, 2015).

518 Also, in the northern area, the increasing SSB estimated by the model after 2005 in all areas

519 (figure 7) is inconsistent with results of Baudron and Fernandes (2015), who suggested a SSB

520 increase mainly in the northern area.

522 By selecting a model with movement occurring only from the northern area to the Celtic Sea,

523 we made the strong assumption that no migration occurs towards the northern area, and

524 between the Bay of Biscay and the Celtic Sea. The availability of relevant tagging data could

525 have allowed to release this strong assumption and test more complex migration design. This

526 simple pattern of migration contrasts with some literature (Alvarez et al., 2004; Baudron and

527 Fernandes, 2015; Casey and Pereiro, 1995; Guichet, 1996; Korta et al., 2015), which

528 discussed potential movements between the Bay of Biscay and the Celtic Sea, even if no data 529 supports this statement. This also contradicts Bertignac et al. (2012) model, which estimates a $53060 \%$ migration to the Celtic Sea, and a $25 \%$ migration to the Bay of Biscay. On the contrary, 
531 the absence of movement in the final spatial model from the Bay of Biscay to the Celtic Sea is

532 consistent with estimates from the model of Drouineau et al. (2010).

534 Migrations were assumed constant over the period and not density dependent. Alternative

535 migration designs including time variability and less constrained designs (some migrations

536 occur during more seasons) were explored (see Appendix A), however the increase of

537 complexity was not supported by the available data, resulting in convergence issues during

538 the estimation procedure. This highlights the needs for improved knowledge on migration and

539 its seasonality (Alvarez et al., 2004; Baudron and Fernandes, 2015; Casey and Pereiro, 1995;

540 Guichet, 1996; Korta et al., 2015) as assuming time-invariant migration rates may have

541 consequences on the estimates of the spatial distribution of the stock in both abundance and

542 size/age structure. Again, tagging data could help estimate migration rates for more complex

543 and realistic models, but it is not currently available.

$545 \quad 4.2$ Lessons from the intermediate models

546 The final spatial model set out to elucidate stock and fleet spatial dynamics and to slightly

547 improve the estimation of abundance spatio-temporal variability and of some fleets landings

548 length compositions. We started the process by adding an implicit spatial fleet design into the

549 current non spatial assessment model which improved the model's predictions of the dynamics

550 of the length composition of some fleets landings. The second significant improvement in the

551 model was introducing explicit spatio-temporal dynamics to create the intermediate 2 model.

552 At this stage, the model accounted for spatial variability through both an explicit spatial

553 structure and spatially explicit selectivity patterns (Hurtado-Ferro et al., 2014). Most of the

554 gains on the estimation of abundance indices spatio-temporal variability were made at this

555 stage. Finally, a seasonal migration was introduced to create the final spatial model, which 
556 improved predictions of some fleets landings length compositions, but worsened the

557 predictions of abundance spatio-temporal variability. This made the final spatial model the

558 most likely for the number of estimated parameters (Appendix A).

559 We also note that we assessed the models abilities to predict abundance spatio-temporal

560 variability basing on goodness of fit to abundance observations. Since these observations have

561 a high inter-annual variability, one could expect that indices on goodness of fit to abundance

562 would be lower than other indices. A perspective to overcome this could be to fit the model to

563 abundance indices trends, rather than to abundance indices.

565 Despite these strengths, the final spatial model has limits, often encountered for complex

566 integrated modeling of spatio-temporal stock dynamics. Firstly, the final spatial model

567 highlights data conflicts (figures 4 and 5) for the northern area and the Celtic Sea surveys,

568 which already existed with the less complex intermediate models. These data conflicts are

569 linked to misspecification of these models (Francis, 2017; Maunder and Piner, 2017) in terms

570 of spatial resolution: a hake population was modelled in each zone, each having its abundance

571 length structure estimated, which conflicts with the data for the Celtic Sea and northern area

572 (figure 4). Preliminary runs increasing the spatial resolution by distinguishing offshore areas

573 from the shelf, for both the Bay of Biscay and the Celtic Sea, resulted in an increase in

574 complexity that was not supported by the current available data (not shown), preventing the

575 estimation procedure from converging. To partly address the misspecification issue,

576 estimating separate selectivity patterns for both NS-IBTS surveys could be an interesting

577 prospect. At the moment, such a misspecification may affect the estimates of spatial

578 distribution of SSB and recruitment discussed in section 4.1.

580 Other issues frequently encountered in complex modeling are the over-parametrization and 
581 identifiability issues. Implementing a more complex model implies adding new processes and

582 parameters that require numerous observations to be accurately estimated. For instance,

583 without appropriate tagging data, it is hard to distinguish whether an abundance increase is

584 linked to movements between areas (Drouineau et al., 2010). The final spatial model and

585 supplementary runs revealed complex interactions between the estimates of migrations,

586 spatial allocation of recruitment, spatial fishing mortalities and spawning stock biomass

587 (Appendix A). This directly affects the perception of the fishery provided by the model, and

588 its ability to provide spatial assessments of the stock and underlines the need for

589 supplementary data to address the model misspecifications.

591 At this stage, several recommendations could be made to further develop this spatial

592 assessment of the northern hake stock. Firstly, model misspecifications should be better

593 identified through, for example, an analysis of performances of fitting and data conflicts

594 (Maunder and Piner, 2017) and then resolved with appropriate modeling hypotheses, if

595 possible. This is of primary importance, as a more complex model does not bring any

596 improvement if misspecified (Punt, 2017).

597 Secondly, a parsimonious modeling approach using the available data and scientific

598 knowledge should be used, to avoid modeling a complex process with confounding estimates

599 for non-identifiable parameters (Appendix A).

601 We also recommend to work on the definition of elements of the estimation procedure, given

602 the difficulties of estimating a high number of parameters in integrated complex modeling

603 (Mahévas et al., comm. pers.). Indeed, given the high number of parameters and the high

604 computational cost for exploring the parameter space, investigating the features of the

605 estimation procedure, such as running the procedure with a large number of initial points, 
606 analyzing available indicators of goodness of fit, analyzing model parameters using likelihood

607 profiles (Cass-Calay et al., 2014), is required to increase the chances of global convergence

608 and correct parameter estimates. Further work to explore parameter values variations with a

609 lower gradient threshold could be an interesting prospect on future models.

\subsection{Towards spatial management}

612 This spatial model is a step towards a spatial assessment of the northern hake stock and its

613 fisheries spatial management. Even though the spatial structure of the model is still coarse,

614 our model takes spatial variations in the stock and fishery dynamics into account and could,

615 therefore, predict management indicators at various scales. In particular, the final spatial

616 model estimates of SSB spatial distribution were variable in time which is different from the

617 current constant Total Allowable Catch (TAC) spatial distribution (ICES, 2016), with a

618 discrepancy between the constant proportion of TAC (3.5\%) allocated to the North Sea and

619 the SSB estimates for the final spatial model increasing towards the end of the time series in

620 the northern area or the recent increase in SSB in the North Sea reported by Baudron and

621 Fernandes (2015). Even if the TAC spatial allocation is made at a different spatial scale from

622 the model described in this paper, the spatial distributions of abundance, fishing mortality and

623 recruitment estimated by the stock assessment model are useful for spatial catch predictions

624 and allocating quotas in different areas. This would help to provide exploitation rates more in

625 line with the potential productivity and fishing pressure at regional levels. Even if this needs

626 to be treated with caution due to the misspecifications identified in the final spatial model, the

627 model is a step towards regionalisation of northern hake fisheries management, as

628 recommended by current European directives and regulations (EU, 2013, 2008).

630 Following these directives and regulations, several regional multiannual management plans to 
631 address mixed fisheries issues are currently being developed (STECF, 2015). These need tools

632 such as a Management Strategy Evaluation (MSE) framework to predict their effects.

633 The results introduced in this manuscript could contribute significantly to the conditioning of

634 a spatial MSE, which may allow the assessment of stock management measures in mixed

635 demersal fisheries, especially spatially-explicit measures. The MSE could use the spatial stock

636 assessment model coupled to a fisheries simulation model, such as ISIS-Fish (Mahévas and

637 Pelletier, 2004; Pelletier et al., 2009), which has already been used in a MSE for other mixed

638 fisheries (Marchal and Vermard, 2013).

639

640 Acknowledgements

641 We would like to thank IFREMER and the Pays de la Loire who provided all the funding for

642 this study. We also thank

643 - all the commercial and survey data providers

644 - the participants in the surveys and sampling programs that collected the data used in our

645 study

646 - the Stock Synthesis 3 and r4ss communities for providing SS3 executables, resources, and

647 help on SS3 and r4ss R library.

648 We also thank André Punt and an anonymous reviewer who helped us to improve the quality 649 of this manuscript. 


\section{Figures and tables}

Figure 1: Map of the areas modelled in the final spatial model. Areas are delineated by thick black lines, area names are in black, bold, underlined text.

Figure 2: Data availability, one panel per area, one line per fleet and data type. A black line indicates that data is available for the period covered by the line.

Figure 3 : Radar charts for the non spatial, intermediate and final spatial models, giving IndR and IndRMSD values for normalized length structure ofn commercial catch $(A)$, discards $(B)$ and on scientific surveys $(C)$, normalized catch in weight $(D)$, discards by weight $(E)$ and indices of abundance $(F)$ for each fleet and survey. IndR are plotted on the right, and IndRMSD on the left of the radar charts. Opposite indices on the same radar chart are for the same fleet*data category combination. Fleet definitions: GILLONG, all longliners and gillnetters; NEP, Nephrops trawlers; SPTR7 and SPTR8 Spanish trawlers in the Celtic Sea and in the Bay of Biscay respectively; TROTH, all non Spanish, non Nephrops trawlers in the

Bay of Biscay and in the Celtic Sea; OTH, the mixed fleet in the northern area. Fleets are grouped by area: mixed (GILLONG \& TROTH), Bay of Biscay (NEP \& SPTR8), Celtic Sea (SPTR7) and northern area (OTH); see table 2 for surveys areas.

Figure 4 : Final spatial model fit to length -frequency distributions for each commercial fleet /survey and type (landings, discards or survey) aggregated over time steps. The 2 first rows are for the Bay of Biscay fleets (panels A to K), the 2 next rows are for the Celtic Sea

fleets (panels $L$ to $R$ ) and the last row is for the northern area fleets (panels $S$ to $W$ ).

Figure 5: Final spatial model fit to abundance indices for each survey (log scale). The widths of the bands represent twice the standard error. First row is for the Bay of Biscay surveys (panels A to E), second row is for the Celtic Sea surveys (panels $F$ to $H$ ) and the last row is for the northern area surveys (panels I to $K$ ).

Figure 6: Estimates of fishing mortality F (top panel), spawning stock biomass (SSB) in tonnes (middle panel), recruitment in numbers (bottom panel) per time step for the final spatial model (solid) and non spatial model (dashed). The confidence intervals represent twice the standard deviation.

Figure 7: Estimates of fishing mortality F (top left panel), spawning stock biomass (SSB) in tonnes (middle left panel), spatial distribution of recruitment per area and time step (bottom left panel) and migrations per season and age class (middle right panel) for the final spatial model. The confidence intervals represent twice the standard deviation. Uncertainties are provided only for the spatial allocation of recruitment and the migrations, as uncertainties for spatial fishing mortalities and SSB are not implemented in the current Stock Synthesis framework. 


\begin{tabular}{|c|c|c|c|c|}
\hline Model & Non spatial & Intermediate 1 & Intermediate 2 & Spatial model \\
\hline Areas & 1 & 1 & 3 & 3 \\
\hline Fleets & 7 & 8 & 8 & 8 \\
\hline Surveys & 7 & 8 & 11 & 11 \\
\hline $\begin{array}{l}\text { Recruitment } \\
\text { allocation }\end{array}$ & $\begin{array}{l}\text { Seasonal } \\
\text { allocation }\end{array}$ & Seasonal allocation & $\begin{array}{c}\text { Spatio-seasonal } \\
\text { allocation }\end{array}$ & $\begin{array}{l}\text { Spatio-seasonal } \\
\text { allocation }\end{array}$ \\
\hline Migrations & No & No & No & Yes \\
\hline $\begin{array}{l}\text { Fleets/survey } \\
\text { sharing the } \\
\text { same } \\
\text { selectivity } \\
\text { pattern }\end{array}$ & RESSGASC & $\begin{array}{c}\text {-EVHOE } \\
\text {-RESSGASC }\end{array}$ & $\begin{array}{c}\text {-EVHOE } \\
\text {-NS-IBTS } \\
\text {-RESSGASC }\end{array}$ & $\begin{array}{c}\text {-EVHOE } \\
\text {-NS-IBTS } \\
\text {-RESSGASC }\end{array}$ \\
\hline $\begin{array}{c}\text { Number of } \\
\text { estimated } \\
\text { parameters }\end{array}$ & 1208 & 1351 & 1433 & 1434 \\
\hline
\end{tabular}

Table 1: Comparison of the non spatial, intermediate and spatial models main features 


\begin{tabular}{|c|c|c|c|c|}
\hline Fleet & $\begin{array}{l}\text { ICES Sub- } \\
\text { area }\end{array}$ & Description & $\begin{array}{l}\text { Selectivity } \\
\text { pattern }\end{array}$ & Options \\
\hline LONGLINEGILLNET_CS & 7 & Celtic Sea longliners and gillnetters. & Double normal & \\
\hline LONGLINEGILLNET_BOB & 8 & Bay of Biscay longliners and gillnetters. & Double normal & \\
\hline TRAWL_FISH_CS_W & 7 & $\begin{array}{c}\text { Non-Nephrops offshore trawlers in the Celtic Sea, } \\
\text { mainly spanish. }\end{array}$ & $\begin{array}{l}\text { Double normal } \\
\text { Retention : } \\
\text { logistic }\end{array}$ & $\begin{array}{l}\text { Retention estimated for } 1978- \\
1997,1998-2009 \text { and } 2009-2012\end{array}$ \\
\hline TRAWL_FISH_CS_E & $\begin{array}{l}\text { Mainly } 7 \text {, } \\
\text { then } 8\end{array}$ & $\begin{array}{l}\text { Mainly non-Nephrops trawlers on the Celtic Sea shelf, } \\
\text { fewer Nephrops trawlers on the Celtic Sea shelf, even } \\
\text { fewer miscellaneous métiers (no disaggregated data } \\
\text { available) in the Celtic Sea and the Bay of Biscay. }\end{array}$ & Logistic & \\
\hline TRAWL_FISH_BOB_W & 8 & Offshore non-Nephrops trawlers Bay of Biscay. & $\begin{array}{l}\text { Double normal } \\
\text { Retention : } \\
\text { logistic }\end{array}$ & $\begin{array}{l}\text { Retention estimated for 1978- } \\
1997 \text { and 1998-2012 }\end{array}$ \\
\hline TRAWL_FISH_BOB_E & 8 & Shelf non-Nephrops trawlers Bay of Biscay. & Logistic & \\
\hline TRAWL_NEP & 8 & Nephrops trawlers Bay of Biscay. & $\begin{array}{c}\text { Double normal } \\
\text { Retention : } \\
\text { logistic }\end{array}$ & \\
\hline OTHERS & $3 a, 4,5,6$ & $\begin{array}{c}\text { Mix of métiers not in the Bay of Biscay, nor the Celtic } \\
\text { Sea (no disaggregated data available). }\end{array}$ & $\begin{array}{l}\text { Logistic } \\
\text { Retention : } \\
\text { logistic }\end{array}$ & $\begin{array}{l}\text { Selectivity and retention } \\
\text { estimated for 1978-2002, then } \\
\text { random walk between 2003-2012 }\end{array}$ \\
\hline
\end{tabular}

Table 2: Fleets, surveys, and their selectivity and retention (for discarding fleets) patterns in the intermediate and spatial models. 


\begin{tabular}{|c|c|c|c|c|}
\hline Survey & $\begin{array}{c}\text { ICES } \\
\text { Sub-area }\end{array}$ & Description & $\begin{array}{c}\text { Selectivity } \\
\text { pattern }\end{array}$ & Options \\
\hline EVHOE_BOB & 8 & EVHOE Bay of Biscay (autumn) & Double normal & EVHOE_CS selectivity pattern \\
\hline EVHOE_CS & 7 & EVHOE Celtic Sea (autumn) & Double normal & \\
\hline RESSGASCQ1 & 8 & RESSGASC winter & Double normal & \\
\hline RESSGASCQ2 & 8 & RESSGASC spring & Double normal & RESSGASCQ1 selectivity pattern \\
\hline RESSGASCQ3 & 8 & RESSGASC summer & Double normal & RESSGASCQ1 selectivity pattern \\
\hline RESSGASCQ4 & 8 & RESSGASC autumn & Double normal & RESSGASCQ1 selectivity pattern \\
\hline PORCUPINE & 7 & PORCUPINE (summer) & Double normal & \\
\hline IGFS & 7 & IGFS (autumn) & Double normal & \\
\hline $\begin{array}{l}\text { SWC-IBTS (Intermediate } 2 \\
\text { and spatial models only) }\end{array}$ & 6 & SWC-IBTS (autumn) & Double normal & \\
\hline $\begin{array}{l}\text { NS-IBTSQ1 (Intermediate } 2 \\
\text { and spatial models only) }\end{array}$ & 4 & NS-IBTS winter & Double normal & \\
\hline $\begin{array}{l}\text { NS-IBTSQ3 (Intermediate } 2 \\
\text { and spatial models only) }\end{array}$ & 4 & NS-IBTS summer & Double normal & NS-IBTSQ1 selectivity pattern \\
\hline
\end{tabular}

Table 2 continued: Fleets, surveys, and their selectivity and retention (for discarding fleets) patterns in the intermediate and spatial models. 


\begin{tabular}{|c|c|c|c|c|}
\hline Quarter & FromlTo & Bay of Biscay & Celtic Sea & Northern area \\
\hline \multirow{3}{*}{1} & Bay of Biscay & $1-\mathrm{x} 1$ & $\mathrm{x} 1$ & 0 \\
\cline { 2 - 5 } & Celtic Sea & 0 & $1-\mathrm{x} 2$ & $\mathrm{x} 2$ \\
\cline { 2 - 5 } & Northern area & 0 & 0 & 1 \\
\hline \multirow{3}{*}{2} & Bay of Biscay & 1 & 0 & 0 \\
\cline { 2 - 5 } & Celtic Sea & $\mathrm{x} 3$ & $1-\mathrm{x} 3-\mathrm{x} 4$ & $\mathrm{x} 4$ \\
\cline { 2 - 5 } & Northern area & 0 & 0 & 1 \\
\cline { 2 - 5 } & Bay of Biscay & 1 & 0 & 0 \\
\cline { 2 - 5 } & Celtic Sea & $\mathrm{x} 5$ & $1-\mathrm{x} 5$ & $1-\mathrm{x} 6$ \\
\hline \multirow{2}{*}{4} & Northern area & 1 & 0 & 0 \\
\cline { 2 - 5 } & Bay of Biscay & $\mathrm{x} 7$ & $1-\mathrm{x} 7$ & 0 \\
\cline { 2 - 5 } & Celtic SeaNorthern area & 0 & $\mathrm{x} 8$ & $1-\mathrm{x} 8$ \\
\cline { 2 - 5 } & Northern area & 0 & 0 & 0 \\
\hline
\end{tabular}

Table 3: Proportion of fish moving from an area (rows) to another area (columns) for each quarter. Each xi is a pair of parameter values, one for age 2, one for ages 3 and above. There is no migration under age 2, a linear interpolation is made between ages 2 and 3 . 


\section{References}

Akaike, H., 1974. A new look at the statistical model identification. IEEE Trans. Autom. Control 19, 716-723. doi:10.1109/TAC.1974.1100705

Alvarez, P., Fives, J., Motos, L., Santos, M., 2004. Distribution and abundance of European hake Merluccius merluccius (L.), eggs and larvae in the North East Atlantic waters in 1995 and 1998 in relation to hydrographic conditions. J. Plankton Res. 26, 811-826. doi:10.1093/plankt/fbh074

Baudron, A.R., Fernandes, P.G., 2015. Adverse consequences of stock recovery: European hake, a new "choke" species under a discard ban? Fish Fish. 16, 563-575. doi:10.1111/faf.12079

Bertignac, M., Fernández, C., Methot, R., 2012. Preliminary spatially disaggregated stock assessment of northern hake, a widely distributed stock of the north-east Atlantic. ICES-CIEM Annual Science Conference, Bergen, Norway (17th - 21st September 2012).

Cadrin, S.X., Secor, D.H., 2009. Accounting for Spatial Population Structure in Stock Assessment: Past, Present, and Future, in: Beamish, RJ and Rothschild, BJ (Ed.), Future of Fisheries Science in North America, Fish and Fisheries Series. Natl Marine Fisheries Serv; Dept Fisheries \& Ocean Canada; AIFRB, pp. 405-426. doi:10.1007/978-1-4020-9210-7_22

Casey, J., Pereiro, J., 1995. European hake (M. merluccius) in the North-east Atlantic, in: Hake. Springer, pp. 125-147.

Cass-Calay, S., Porch, C., Goethel, D., Smith, M., Matter, V., McCarthy, K., 2015. Stock Assessment of Red Snapper in the Gulf of Mexico, 1872-2013, with Provisional 2014 Landings. SEDAR Update Assess.

Cass-Calay, S.L., Tetzlaff, J.C., Cummings, N.J., Isely, J.J., 2014. Model diagnostics for stock synthesis 3: examples from the 2012 assessment of cobia in the US Gulf of Mexico. Collect Vol Sci Pap ICCAT 70, 2069-2081.

Cope, J.M., Punt, A.E., 2011. Reconciling stock assessment and management scales under conditions of spatially varying catch histories. Fish. Res. 107, 22-38. doi:10.1016/j.fishres.2010.10.002

Day, J., Haddon, M., Hillary, R., 2015. Stock Assessment of the macquarie Island fishery for Patagonian toothfish (Dissostichus eleginoides) using data up to and including August 2014. CSIRO, Australia.

de Pontual, H., Groison, A.L., Piñeiro, C., Bertignac, M., 2006. Evidence of underestimation of European hake growth in the Bay of Biscay, and its relationship with bias in the agreed method of age estimation. ICES J. Mar. Sci. 63, 1674-1681.

Drouineau, H., 2008. Développement et ajustement d'un modèle de dynamique des populations structuré en longueur et spatialisé appliqué au stock Nord de merlu (Merluccius merluccius). École Nationale Supérieure d'Agronomie de Rennes.

Drouineau, H., Mahévas, S., Bertignac, M., Duplisea, D., 2010. A length-structured spatially explicit model for estimating hake growth and migration rates. ICES J. Mar. Sci. 67, 1697-1709. doi:10.1093/icesjms/fsq042

EC, 2004. Council Regulation (EC) No 811/2004 of 21 April 2004 establishing measures for the recovery of the Northern hake stock, http://eur-lex.europa.eu/legalcontent/EN/TXT/PDF/?uri=CELEX:32004R0811\&qid=1507799156511\&from=EN.

EC, 2002. Commission Regulation (EC) No 494/2002 of 19 March 2002 establishing additionaltechnicalmeasures for the recovery of the stock of hake in ICES sub-areas III, IV, V, VI and VII and ICES divisions VIII a, b, d, e, http://eur-lex.europa.eu/legal- 
content/EN/TXT/PDF/?uri=CELEX:32002R0494\&from=EN.

EC, 2001a. Commission Regulation (EC) No 1162/2001 of 14 June 2001 establishing

measures for the recovery of the stock of hake in ICES sub-areas III, IV, V, VI and VII

and ICES divisions VIII a, b, d, e and associated conditions for the control of activities of fishing vessels - Proposal by Spain, under Article 15(3) of Regulation (EEC) No 3760/92, for the amendment of Commission Regulation (EC) No 1162/2001, http://eur-lex.europa.eu/legal-content/EN/TXT/PDF/? uri=CELEX:32001R1162\&qid=1507798251399\&from=EN.

EC, 2001b. Commission Regulation (EC No 2602/2001 of 27 December 2001 establishing additional technical measures for the recovery of the stock of hake in ICES subareas III, IV, V, VI and VII and ICES Divisions VIIIa,b,d,e, http://eur-lex.europa.eu/legalcontent/EN/TXT/PDF/?uri=CELEX:32001R2602\&qid=1507798298100\&from=EN

EU, 2014. Directive 2014/89/EU of the European Parliament and of the Council of 23 July 2014 establishing a framework for maritime spatial planning, http://eur-

lex.europa.eu/legal-content/EN/TXT/PDF/? uri=CELEX:32014L0089\&qid=1507799295372\&from $=$ EN.

EU, 2013. Regulation (EU) No 1380/2013 of the European Parliament and of the Council of 11 December 2013 on the Common Fisheries Policy, amending Council Regulations (EC) No 1954/2003 and (EC) No 1224/2009 and repealing Council Regulations (EC) No 2371/2002 and (EC) No 639/2004 and Council Decision 2004/585/EC, http://eurlex.europa.eu/legal-content/EN/TXT/PDF/? uri=CELEX:32013R1380\&qid $=1507799258402 \&$ from $=E N$.

EU, 2008. Directive 2008/56/EC of the European Parliament and of the Council of 17 June 2008 establishing a framework for community action in the field of marine environmental policy (Marine Strategy Framework Directive), http://eurlex.europa.eu/legal-content/EN/TXT/PDF/? uri=CELEX:32008L0056\&qid=1507799216369\&from $=E N$.

Fournier, D.A., Skaug, H.J., Ancheta, J., Ianelli, J., Magnusson, A., Maunder, M.N., Nielsen, A., Sibert, J., 2012. AD Model Builder: using automatic differentiation for statistical inference of highly parameterized complex nonlinear models. Optim. Methods Softw. 27, 233-249. doi:10.1080/10556788.2011.597854

Francis, R.I.C.C., 2017. Revisiting data weighting in fisheries stock assessment models. Fish. Res. 192, 5-15.

Garrison, T.M., Hamel, O.S., Punt, A.E., 2011. Can data collected from marine protected areas improve estimates of life-history parameters? Can. J. Fish. Aquat. Sci. 68, 17611777. doi:10.1139/F2011-073

Gertseva, V.V., Cope, J.M., 2011. Population dynamics of splitnose rockfish (Sebastes diploproa) in the Northeast Pacific Ocean. Ecol. Model. 222, 973-981. doi:10.1016/j.ecolmodel.2010.12.003

Guichet, R., 1996. Le merlu Européen (Merluccius merluccius L.).

Hampton, J., Fournier, D., 2001. A spatially disaggregated, length-based, age-structured population model of yellowfin tuna (Thunnus albacares) in the western and central Pacific Ocean. Mar. Freshw. Res. 52, 937-963. doi:10.1071/MF01049

Hurtado-Ferro, F., Punt, A.E., Hill, K.T., 2014. Use of multiple selectivity patterns as a proxy for spatial structure. Fish. Res. 158, 102-115. doi:10.1016/j.fishres.2013.10.001

ICES, 2016. Report of the Working Group for the Bay of Biscay and the Iberian waters Ecoregion (WGBIE). 13-19 May 2016, ICES HQ, Copenhagen, Denmark, http://ices.dk/sites/pub/Publication\%20Reports/Expert\%20Group $\% 20$ Report/acom/2016/WGBIE/01\%20WGBIE\%20Report\%20-\%20Report\%20of $\% 20$ the $\% 20$ Working\%20Group $\% 20$ for $\% 20$ the $\% 20$ Bay $\% 20$ of $\% 20$ Biscay $\% 20$ and 
\%20the\%20Iberian\%20Waters\%20Ecoregion\%20\%28WGBIE\%29.pdf.

ICES, 2015. Report of the Workshop to consider FMSY ranges for stocks in ICES categories

1 and 2 in Western Waters (WKMSYREF4). 13-16 October 2015, Brest, France,

http://ices.dk/sites/pub/Publication\%20Reports/Expert\%20Group

\%20Report/acom/2015/WKMSYREF4/01\%20WKMSYREF4\%20Report.pdf.

ICES, 2014. Report of the Benchmark Workshop on Southern megrim and hake

(WKSOUTH), 3-7 February 2014, ICES HQ, Copenhagen, Denmark,

http://ices.dk/sites/pub/Publication\%20Reports/Expert\%20Group

\%20Report/acom/2014/WKSOUTH\%202014/02\%20WKSOUTH13\%20report.pdf.

ICES, 2010. Report of the Benchmark Workshop on Roundfish (WKROUND), 9-16 February

2010, Copenhagen, Denmark, http://ices.dk/sites/pub/Publication\%20Reports/Expert

\%20Group\%20Report/acom/2010/WKROUND\%202010/final_wkround_2010.pdf.

Kolody, D., 2010. A Spatially-Structured Stock Synthesis Assessment of the Indian Ocean

Swordfish Fishery 1950-2008, including Special Emphasis on the SW Region. IOTC2010-WPB-05.

Korta, M., García, D., Santurtún, M., Goikoetxea, N., Andonegi, E., Murua, H., Álvarez, P., Cerviño, S., Castro, J., Murillas, A., 2015. European hake (Merluccius merluccius) in the Northeast Atlantic Ocean, in: Hakes: Biology and Exploitation. John Wiley \& Sons, Ltd, pp. 1-37.

Mahévas, S., Pelletier, D., 2004. ISIS-Fish, a generic and spatially explicit simulation tool for evaluating the impact of management measures on fisheries dynamics. Ecol. Model. $171,65-84$.

Marchal, P., Vermard, Y., 2013. Evaluating deepwater fisheries management strategies using a mixed-fisheries and spatially explicit modelling framework. ICES J. Mar. Sci. 70, 768-781.

Maunder, M.N., Piner, K.R., 2017. Dealing with data conflicts in statistical inference of population assessment models that integrate information from multiple diverse data sets. Fish. Res. 192, 16-27. doi:10.1016/j.fishres.2016.04.022

McGilliard, C.R., Punt, A.E., Methot, R.D., Jr., Hilborn, R., 2015. Accounting for marine reserves using spatial stock assessments. Can. J. Fish. Aquat. Sci. 72, 262-280. doi:10.1139/cjfas-2013-0364

Methot, R.D., Jr., Wetzel, C.R., 2013. Stock synthesis: A biological and statistical framework for fish stock assessment and fishery management. Fish. Res. 142, 86-99.

Montenegro, C., Maunder, M.N., Zilleruelo, M., 2009. Improving management advice through spatially explicit models and sharing information. Fish. Res. 100, 191-199. doi:10.1016/j.fishres.2009.07.006

Moustakas, A., Silvert, W., Dimitromanolakis, A., 2006. A spatially explicit learning model of migratory fish and fishers for evaluating closed areas. Ecol. Model. 192, 245-258. doi:http://dx.doi.org/10.1016/j.ecolmodel.2005.07.007

Murua, H., 2010. The biology and fisheries of European Hake, Merluccius merluccius, in the North-East Atlantic, in: Lesser, M (Ed.), Advances in Marine Biology, Advances in Marine Biology. pp. 97-154.

Pelletier, D., Mahevas, S., 2005. Spatially explicit fisheries simulation models for policy evaluation. Fish Fish. 6, 307-349.

Pelletier, D., Mahévas, S., Drouineau, H., Vermard, Y., Thebaud, O., Guyader, O., Poussin, B., 2009. Evaluation of the bioeconomic sustainability of multi-species multi-fleet fisheries under a wide range of policy options using ISIS-Fish. Ecol. Model. 220, 1013-1033.

Poulard, J., 2001. Distribution of hake (Merluccius merluccius, Linnaeus, 1758) in the Bay of Biscay and the Celtic sea from the analysis of French commercial data. Fish. Res. 50, 
173-187. doi:10.1016/S0165-7836(00)00250-2

Punt, A.E., 2017. Strategic management decision-making in a complex world: quantifying, understanding, and using trade-offs. ICES J. Mar. Sci. 74, 499-510. doi:10.1093/icesjms/fsv193

Punt, A.E., Haddon, M., Tuck, G.N., 2015. Which assessment configurations perform best in the face of spatial heterogeneity in fishing mortality, growth and recruitment? A case study based on pink ling in Australia. Fish. Res. 168, 85-99. doi:10.1016/j.fishres.2015.04.002

Quéro, J.-C., Vayne, J.-J., 1997. Les poissons de mer des pêches françaises. Delachaux et Niestlé.

Russo, T., Parisi, A., Garofalo, G., Gristina, M., Cataudella, S., Fiorentino, F., 2014. SMART: A Spatially Explicit Bio-Economic Model for Assessing and Managing Demersal Fisheries, with an Application to Italian Trawlers in the Strait of Sicily. PLoS ONE 9. doi:10.1371/journal.pone.0086222

Sharma, R., 2014. An age-, sex- and spatially-structured stock assessment of the Indian Ocean Swordfish fishery 1950-2012, using Stock Synthesis. IOTC-2014-WPB-12-26.

STECF, 2015. Multiannual management plans SWW and NWW(STECF-15-08) (No. EUR 27406 EN, JRC 96964), Publications Office of the European Union, Luxembourg, http://publications.jrc.ec.europa.eu/repository/bitstream/JRC96964/stecf\%201508\%20-\%20maps\%20sww\%20and\%20nww_jrc96964.pdf.

Taylor, K., 2001. Summarizing multiple aspects of model performance in a single diagram. J. Geophys. Res.-Atmospheres 106, 7183-7192. doi:10.1029/2000JD900719

Thorson, J., Wetzel, C., 2015. The status of canary rockfish (Sebastes pinniger) in the California Current in 2015. Pac. Fish. Manag. Counc. 7700, 97200-1384.

Viallefont, A., Lebreton, J., Reboulet, A., Gory, G., 1998. Parameter Identifiability and Model Selection in Capture-Recapture Models: A Numerical Approach. Biom. J. 40, $313-$ 325. doi:10.1002/(SICI)1521-4036(199807)40:3<313::AID-BIMJ313>3.0.CO;2-2

Werner, K.-M., Staby, A., Geffen, A.J., 2016. Temporal and spatial patterns of reproductive indices of European hake (Merluccius merluccius) in the northern North Sea and Norwegian coastal areas. Fish. Res. 183, 200-209. doi:http://dx.doi.org/10.1016/j.fishres.2016.06.008

Woillez, M., Poulard, J.-C., Rivoirard, J., Petitgas, P., Bez, N., 2007. Indices for capturing spatial patterns and their evolution in time, with application to European hake (Merluccius merluccius) in the Bay of Biscay. ICES J. Mar. Sci. 64, 537-550. doi:10.1093/icesjms/fsm025 
Figure 1

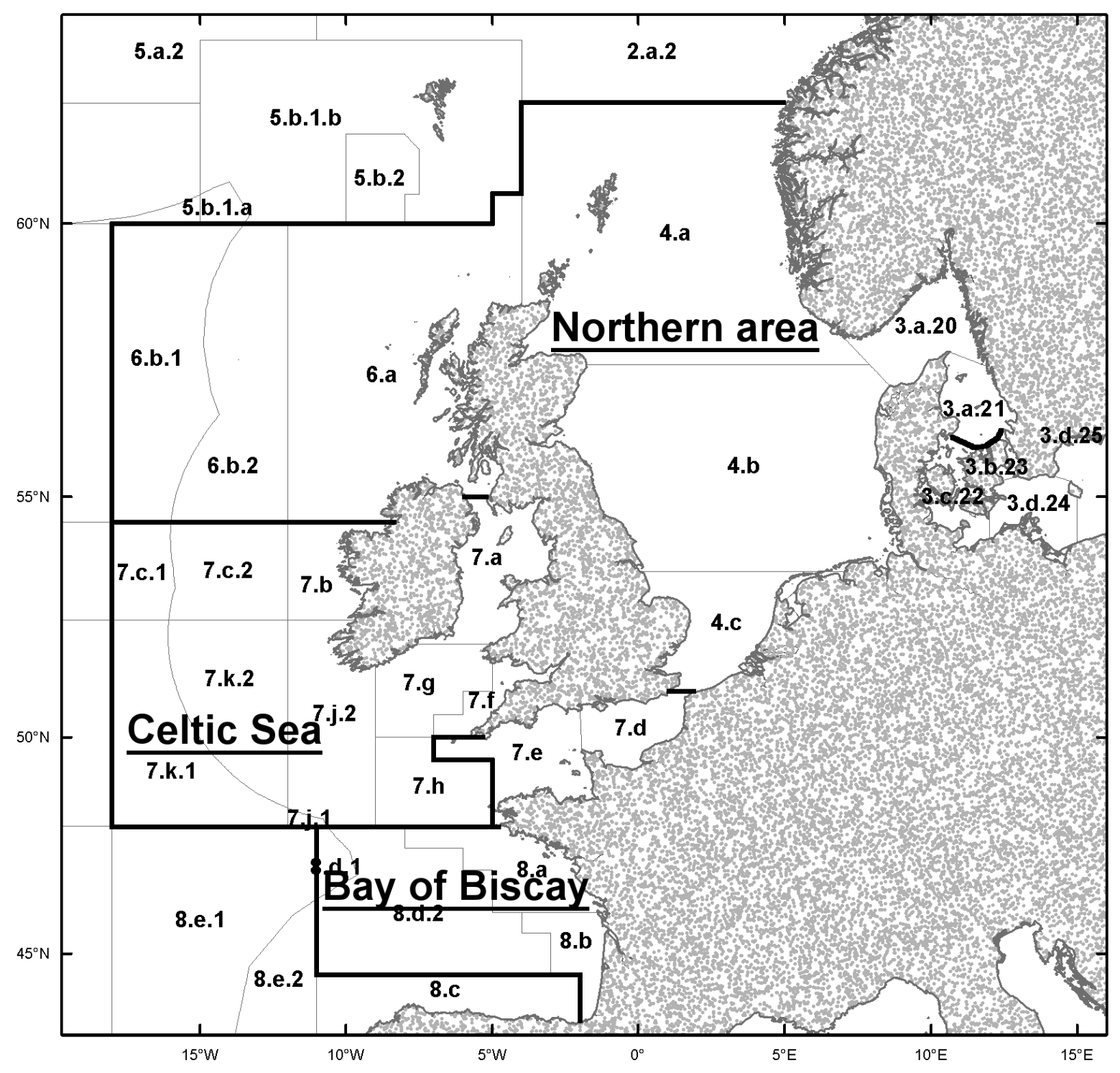

Figure 2
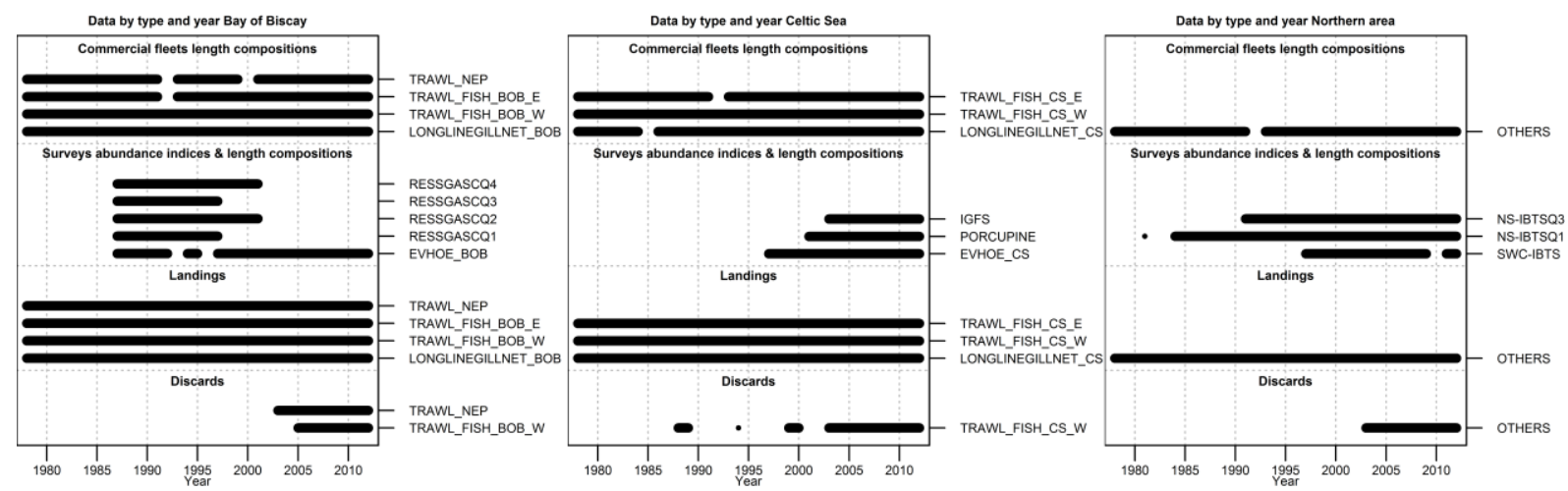
Figure 3

Length distribution
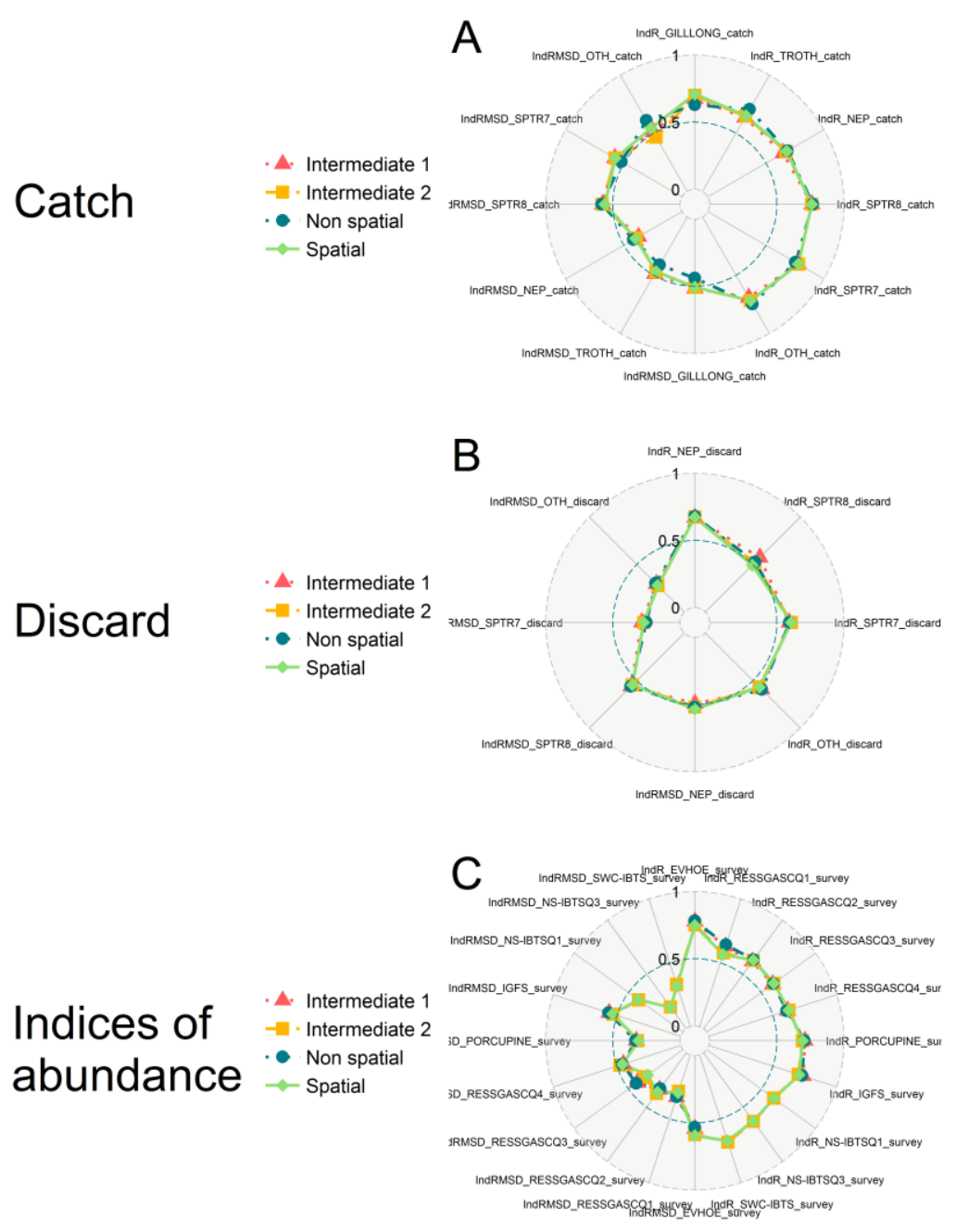

Total in weight and abundance indices
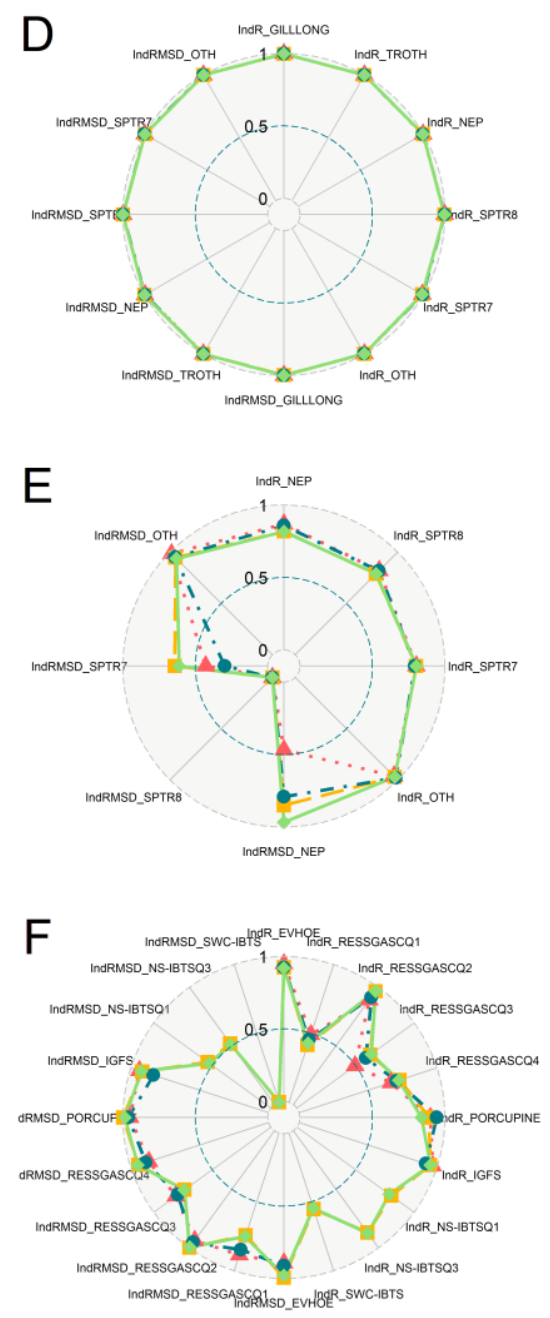
Figure 4

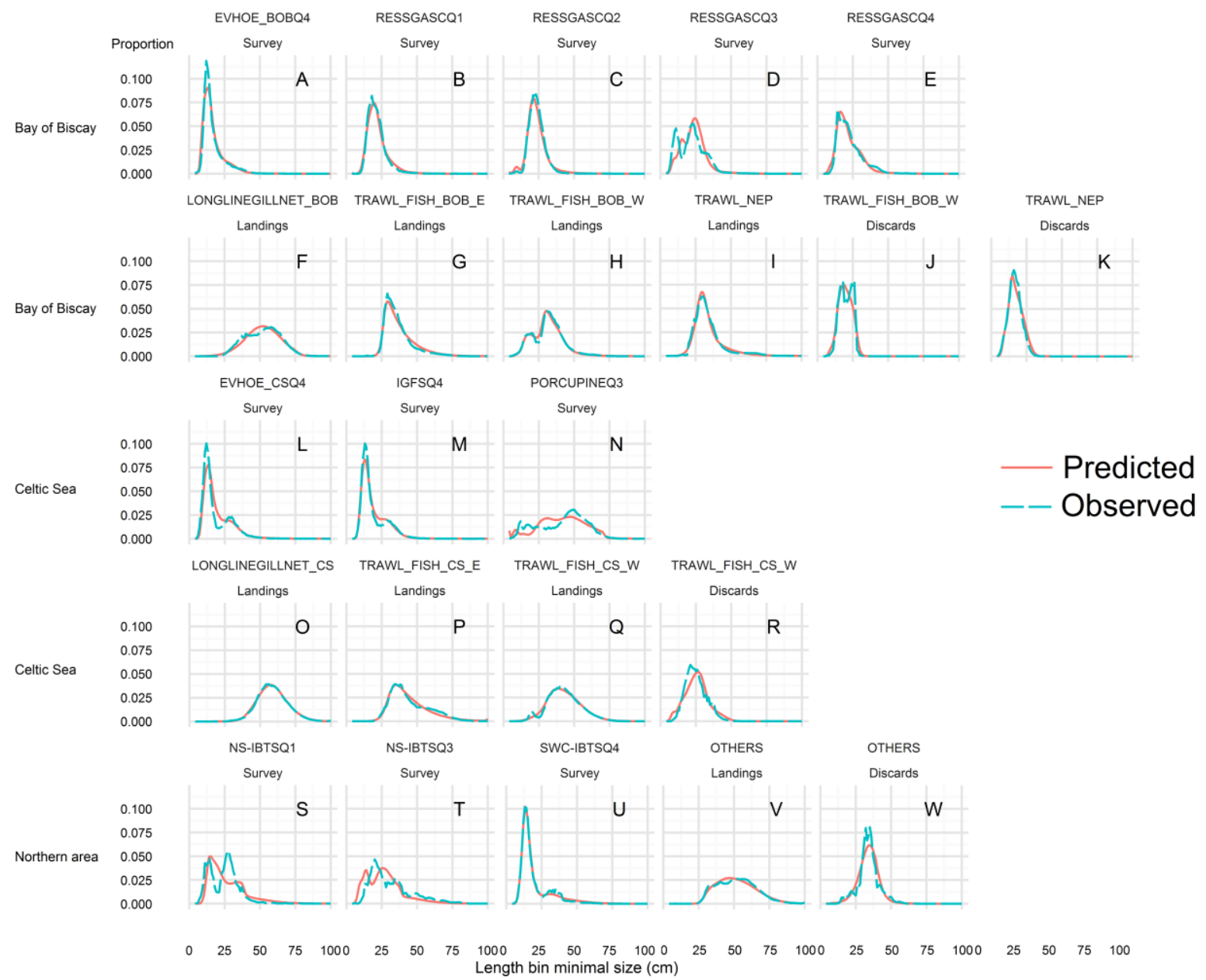


Figure 5

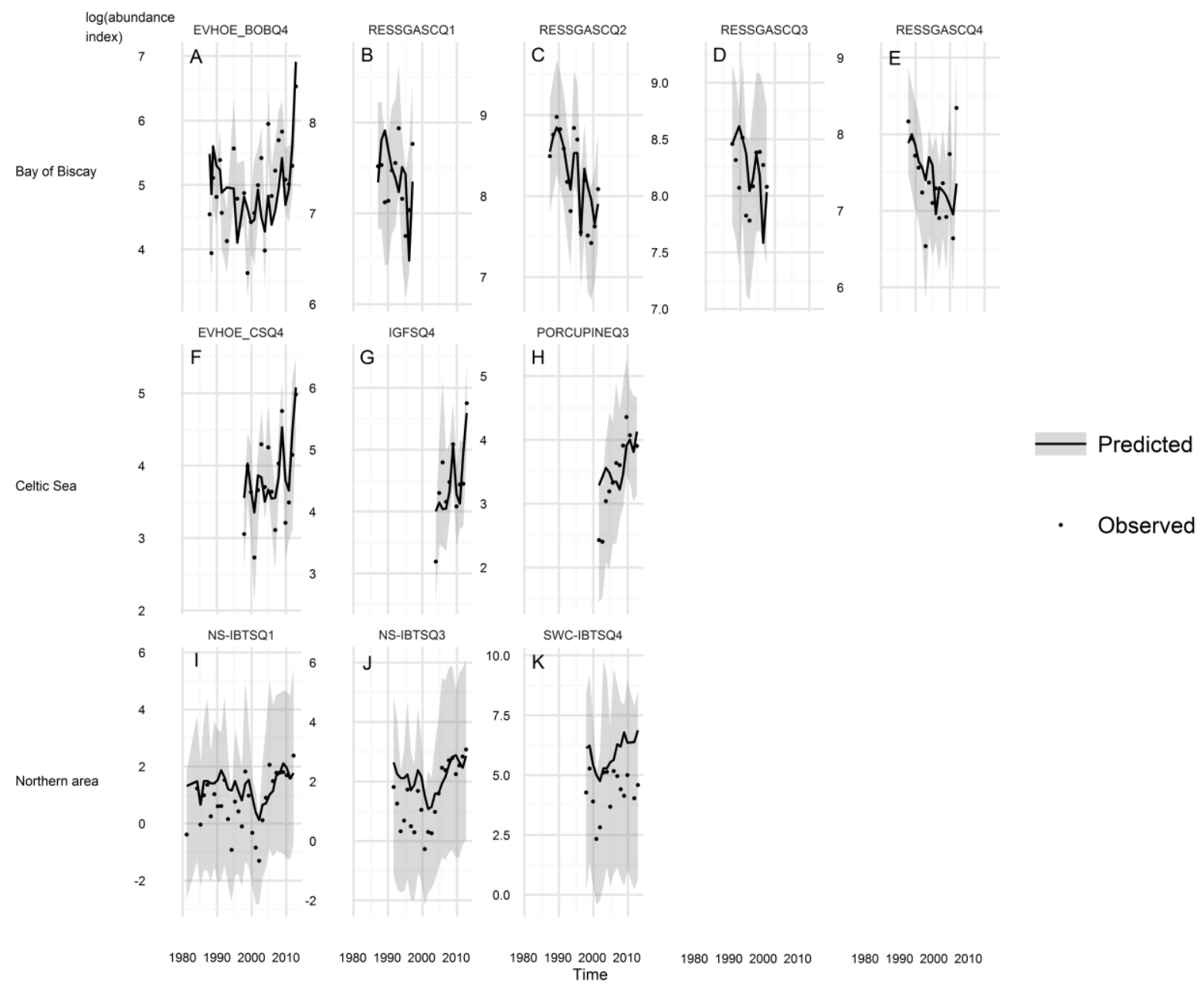


Figure 6

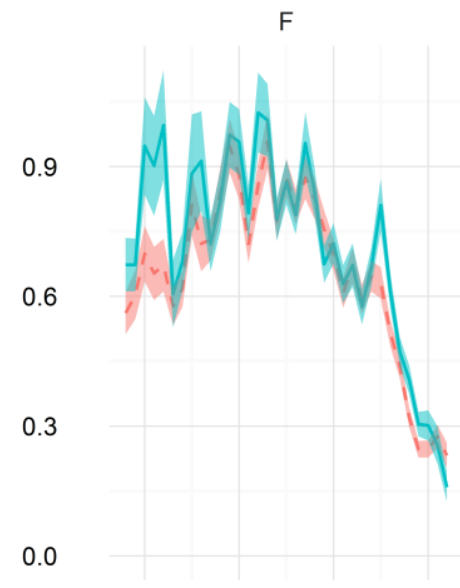

SSB (tonnes)
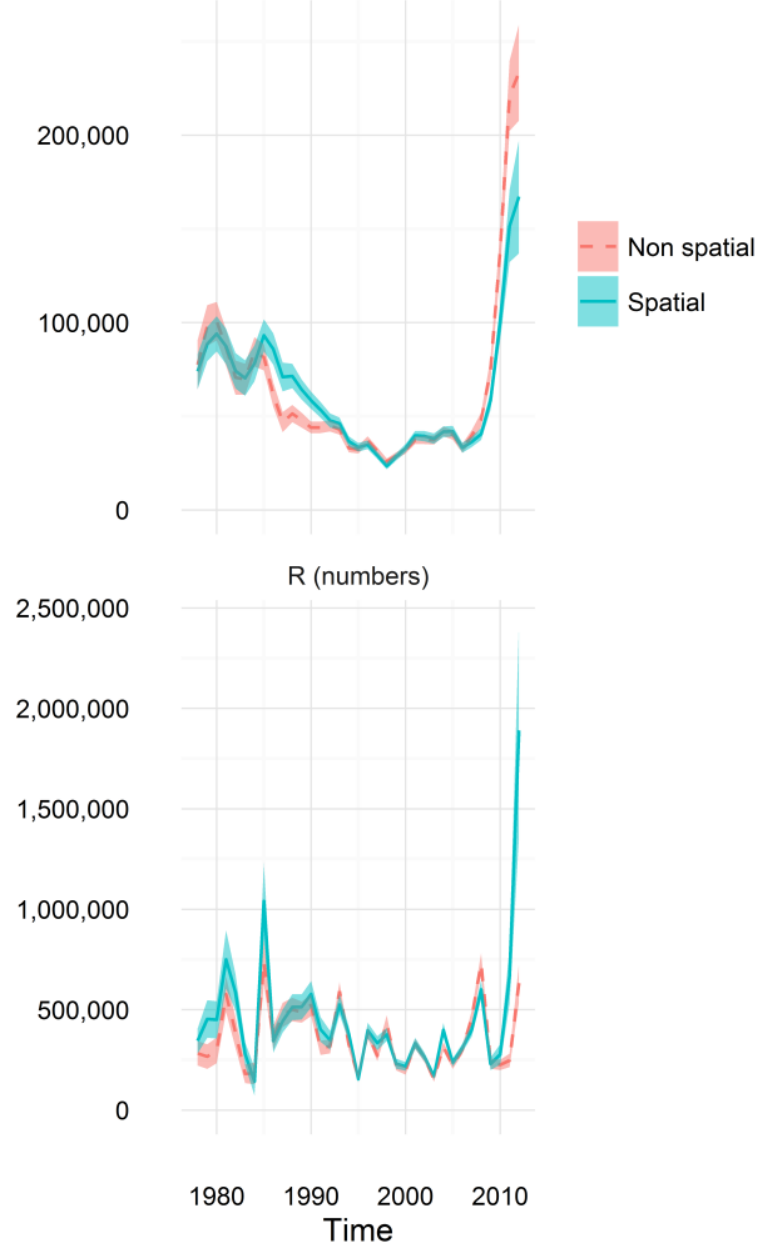
Figure 7
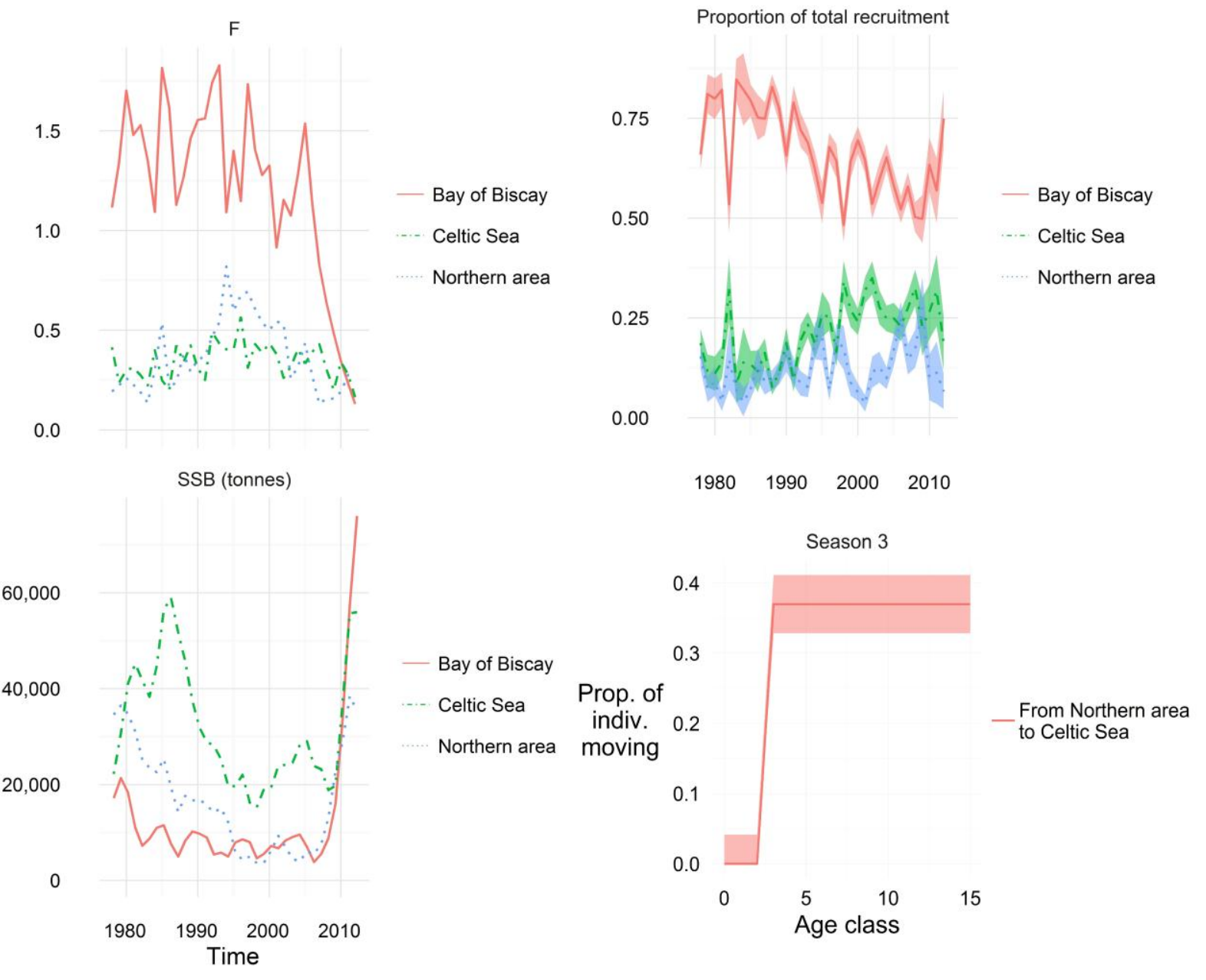